\title{
Os (entre)laços com a terra, o lar e o lugar: topofilia e percepção ambiental de uma comunidade rural da Bahia
}

\author{
The (inter)laces with the land, the home and the place: topophilia and \\ environmental perception of a rural community of Bahia
Los (entre)lazos con la tierra, el hogar y el lugar: topofilia y percepción ambiental de una comunidad rural de Bahia

\author{
Damile de Jesus Ferreira ${ }^{1}$ \\ Christiana Cabicieri Profice ${ }^{1}$
}

Recebido em 12/12/2019; revisado e aprovado em 07/05/2020; aceito em 17/07/2020 DOI: http://dx.doi.org/10.20435/inter.v22i1.2855

\begin{abstract}
Resumo: Com o aumento da constante preocupação com as questões ambientais, a percepção ambiental pretende entender a relação do ser humano com a natureza e quais condicionantes direcionam seu comportamento e suas atitudes em relação ao meio. Assim, o objetivo deste trabalho foi de compreender a percepção ambiental dos moradores da comunidade rural do Barrocão (Uruçuca, BA), identificando a relação topofílica estabelecida entre os moradores com o lugar. O estudo é uma pesquisa qualitativa, em que teve como método de coleta o uso de entrevistas semiestruturadas com os moradores, partindo de um roteiro elaborado conforme as orientações metodológicas de percepção ambiental de Whyte (1977). As entrevistas foram realizadas com 13 moradores integrantes da associação comunitária Doces e Segredos da Floresta. Os resultados revelaram que os moradores obtêm um laço afetivo com o lugar em que vivem, estando satisfeitos em morar na comunidade e indicando fatores externos como problemáticos. Constatouse que o sentido de comunidade vai além das delimitações geográficas estabelecidas, sendo fortalecido por sentimentos coletivos compartilhados.
\end{abstract}

Palavras-chave: topofilia; percepção ambiental; comunidade rural.

Abstract: With the increasing concern with environmental issues, environmental perception aims to understand the relationship between human beings and nature and which conditions direct their behavior and attitudes toward the environment. Thus, the objective of this work was to understand the environmental perception of the rural community of Barrocão (Uruçuca, BA) residents, identifying the topophilic relationship established among the residents with the place. The study is a qualitative research, in which the method of collection was the use of semi-structured interviews with the residents, starting from a script developed according to the methodological guidelines of environmental perception of Whyte (1977). We conducted the interviews with 13 residents of the community association Sweets and Forest Secrets (Doces e Segredos da Floresta). The results revealed that the residents get an affective bond with the place they live, being satisfied to live in the community and indicating external factors as problematic. We verified that the sense of community goes beyond the established geographical delimitations, being strengthened by shared collective feelings. Keywords: topophilia; environmental perception; rural community.

Resumen: Con el aumento de la constante preocupación con las cuestiones ambientales, la percepción ambiental pretende entender la relación del ser humano con la naturaleza y cuáles condicionantes dirigen su comportamiento y sus actitudes en relación al medio. Así, el objetivo de este trabajo fue de comprender la percepción ambiental de los habitantes de la comunidad rural del Barrocão (Uruçuca, BA), identificando la relación topofilica establecida entre los moradores con el lugar. El estudio es una investigación cualitativa, en el cual tuvo como método de recolección el uso de entrevistas semiestructuradas con los moradores, partiendo de un guion elaborado según las orientaciones metodológicas de percepción ambiental de Whyte (1977). Las entrevistas se realizaron con 13 residentes integrantes de la asociación comunitaria Dulces y Secretos del Bosque (Doces e Segredos da Floresta). Los resultados revelaron que los residentes obtienen un lazo afectivo con el lugar en que viven, estando satisfechos de vivir en la comunidad e indicando factores externos como problemáticos. Se constató que el sentido de comunidad va más allá de las delimitaciones geográficas establecidas, siendo fortalecido por sentimientos colectivos compartidos.

Palabras claves: topofilia; percepción ambiental; comunidad rural.

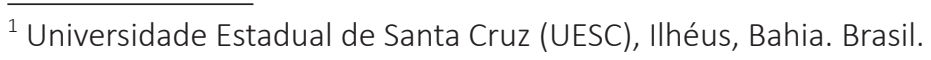




\section{INTRODUÇÃO}

O olhar individual e coletivo sobre o ambiente em que os indivíduos estão inseridos traduz as experiências vividas, compartilhadas e percebidas, possibilitando a construção de sua identidade permeada por memórias e lembranças. A imagem ambiental que é projetada por cada um é constituída por três componentes fundamentais: identidade, estrutura e significado. O significado é o componente precursor para uma nova leitura do meio, envolvendo uma relação de caráter prático ou emocional entre o objeto e o observador (LYNCH, 2011).

Cada indivíduo percebe, reage e responde diferentemente às ações sobre o ambiente em que vive; são os valores presentes nas manifestações resultantes da percepção - cultura, história, religião, classe social e uma série de outros - que influenciam diretamente no processo, o que explica que indivíduos atuantes em um mesmo grupo social expressem atitudes e pensamentos distintos, como também semelhantes. Sendo assim, as relações de influência da comunidade no ambiente e como este influencia o ser humano resultam dos modos culturais de interação do sujeito no espaço. Hall (2006) considera que a interação e o sentimento de pertencimento ao ambiente caracterizam uma identidade cultural, podendo promover o processo de percepção favorável ao ambiente.

Nesse âmbito, os processos perceptivos orientam a relação dos seres humanos com o mundo natural e podem servir como elementos na compreensão de diferentes concepções e propostas de intervenção sobre o ambiente natural. Assim, o meio de perceber a realidade está diretamente interligado aos padrões culturais existentes na comunidade, sendo que, modificando os padrões culturais determinados historicamente, modifica-se a percepção sobre o meio ambiente (MASSON, 2004). Okamoto (2002) explica que as modificações nos padrões citados são resultantes de filtros, que podem ser sensoriais, fisiológicos e culturais.

Pensar o ambiente na forma como é percebido e vivido alimenta o sentimento topofílico de cada sujeito. De acordo com Tuan (2012), a topofilia é o elo afetivo entre a pessoa e o lugar, incluindo os laços afetivos dos seres humanos com o meio ambiente material. Para o autor, o meio ambiente pode não ser a causa direta da topofilia, mas oferece o estímulo sensorial que, ao agir como imagem percebida, dá forma às nossas alegrias e ideais.

No entanto, o processo de organização e interpretação das sensações percebidas pelos indivíduos varia conforme as relações significativas estabelecidas com o ambiente. $O$ sentimento topofílico dos agricultores e moradores de comunidades rurais diferencia-se muito ao daqueles que vivem em centros urbanos ou que vivem de acordo com o status socioeconômico. Para os agricultores e trabalhadores rurais, não existe a externalidade entre o "eu" e a natureza como é vista nas relações alicerçadas pelo paradigma antropocêntrico, em que o ser humano se tornou a medida autorreferente para todas as coisas (ALVES, 2012). Esse dualismo do mundo funda-se na suposta separação real e objetiva entre o ser humano e natureza, corpo e mente.

Assim, de acordo com Tuan (2012), a topofilia do agricultor está baseada na intimidade física com a terra e sua dependência material, considerando que a agricultura de subsistência consiste em um sistema que visa fundamentalmente à sobrevivência do agregado familiar (CORREIA, 2013), de forma a suprir as necessidades alimentares das famílias, sem o objetivo do lucro.

Para além da intimidade física do contato, a terra se configura como um repositório de lembranças pelos moradores, sejam elas individuais, sejam elas coletivas. Os "lugares de memória" descritos por Lé Bossé (2004) são locais de expressão privilegiados que estimulam a capacidade de recordar, preservar e perpetuar um passado, fazendo parte de um sentimento identitário. A atribuição simbólica e a noção de pertencimento de cada indivíduo com o seu local de vivência 
são permeadas por sentimentos de esperança, amor, gratidão, reconhecimento e coletividade, podendo ser compartilhadas suas crenças, tradições e histórias com os demais.

Nessa perspectiva, este trabalho tem como objetivo compreender a percepção ambiental dos moradores da comunidade rural do Barrocão, no distrito de Serra Grande (BA), identificando e analisando a relação afetiva dos moradores com a comunidade e o ambiente que o circunda. Esta categoria ajudou a descrever e nos aproximar da visão de mundo de cada entrevistado, de forma a concretizar-se na experiência pessoal, compreendendo os laços entre esses indivíduos e o meio ambiente, revelando sentimentos que não são visíveis em seus relatos, mas que estão presentes em todo envolvimento com a terra e com a vida comunitária.

\section{MATERIAIS E MÉTODOS}

\subsection{Conhecendo a área de estudo}

A pesquisa foi realizada na comunidade do Barrocão (Figura 1), localizada a $5 \mathrm{~km}$ do Parque Estadual da Serra do Conduru (PESC), a $13 \mathrm{~km}$ de Serra Grande e a $26 \mathrm{~km}$ da sede de Uruçuca, por via não pavimentada (GOMES, 2012), na região sul do Estado da Bahia. De todas as comunidades do entorno do PESC, ela é a que fica mais próxima da sede do parque, encontrando-se em sua zona de amortecimento (ZA). Além de a comunidade integrar a ZA, ela também está inserida dentro da APA da Costa de Itacaré/Serra Grande, BA.

O Barrocão é uma comunidade estritamente rural, apesar de seu processo de ocupação territorial ter sido baseado no extrativismo do pau-brasil e de outras madeiras nobres, na canade-açúcar, no café, no cacau, na pesca e pecuária (BAHIA, 2005). Atualmente, tem como sua principal atividade socioeconômica a agricultura ou atividades relacionadas a ela, produzindo tanto para a subsistência quanto para o comércio.

Figura 1 - Mapa com a localização da comunidade do Barrocão e da Associação Doces Segredos da Floresta

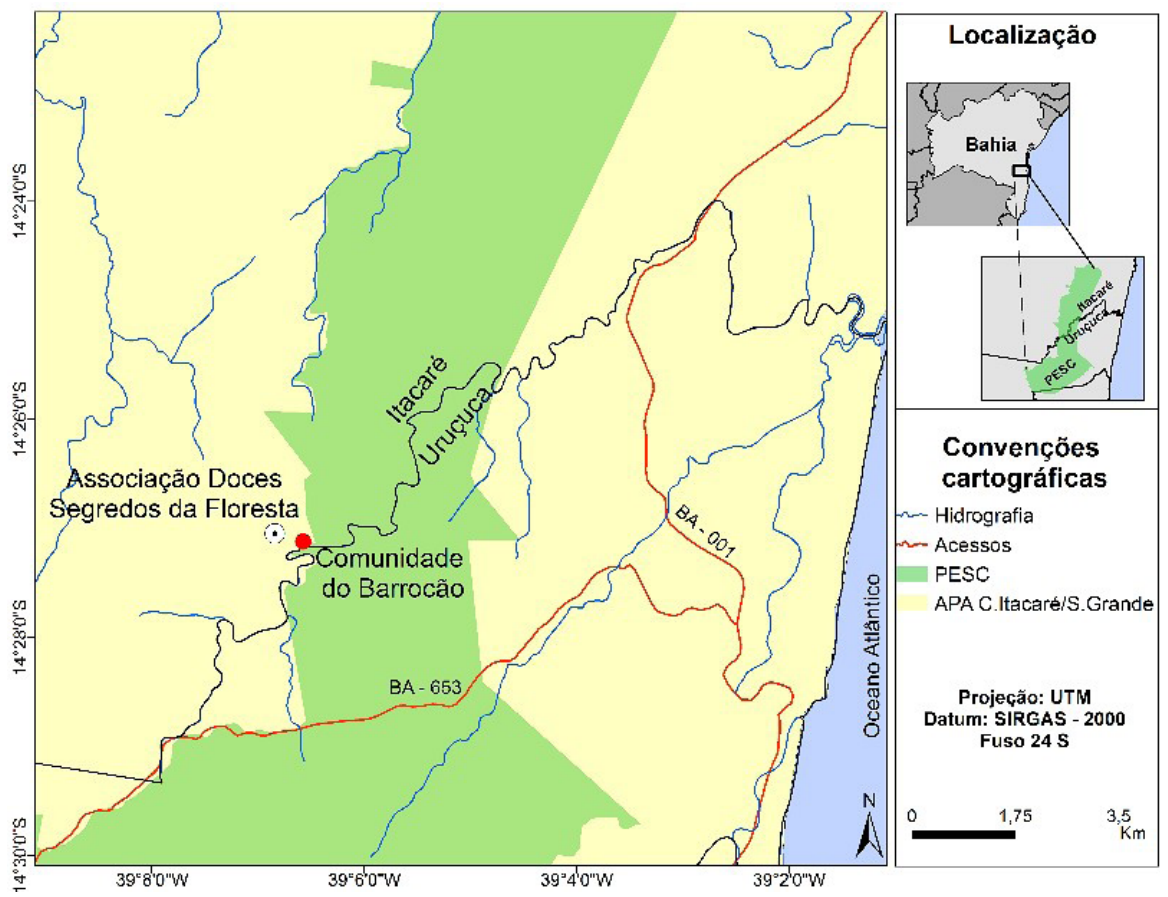

Fonte: autoria própria, em 2017. 
$\mathrm{Na}$ atualidade, existem 80 famílias vivendo na comunidade e, segundo os moradores, este número corresponde ao mínimo de famílias que conseguiram permanecer na área depois da chegada do parque, em 1997, já que muitas delas foram desapropriadas e precisaram deixar seu lugar de origem. Apesar deste cenário, os moradores conseguiram, por meio de associações, uma maneira de se organizar enquanto comunidade.

A Associação Doces Segredos da Floresta, que foi o foco desta pesquisa, foi criada burocraticamente em 14 de dezembro de 2014, mas já realizava atividades desde 2008. A associação contém 13 associados, sendo que 11 são mulheres e apenas dois integrantes são homens, evidenciando a participação expressiva das mulheres nas tomadas de decisões e no fortalecimento associativo. Os agricultores são integrantes dos programas governamentais Programa de Aquisição de Alimentos (PAA) e Programa Nacional de Alimentação Escolar (PNAE), contribuindo para a renda mensal juntamente do comércio na feira livre de Serra Grande e Uruçuca.

\subsection{Procedimentos e enfoques metodológicos}

O trabalho assumiu a perspectiva da investigação qualitativa fenomenológica, já que o eixo norteador da pesquisa foi fundamentado na visão sistêmica e complexa da matriz teórica: a Fenomenologia. A pesquisa fenomenológica trabalha essencialmente com descrições, seja do vivido, seja dos significados presentes nas experiências vividas, que são passíveis de compreensão, análise e interpretação.

Nesse intuito, a interpretação e compreensão da percepção ambiental dos sujeitos da pesquisa foram facilitadas utilizando técnicas de pesquisa de campo elaboradas por Whyte (1977), em sua publicação Guidelines for field studies in Environmental Perception. A autora traz em suas diretrizes três abordagens que, combinadas, orientam no processo investigativo perceptivo: o observar, escutar e interrogar.

Pelo fato de se tratar de uma pesquisa socioambiental, fenomenológica e qualitativa, o contato e envolvimento com a comunidade precede qualquer procedimento metodológico técnico. Após os devidos esclarecimentos sobre a pesquisa, obtenção da concessão de seu consentimento livre e esclarecido e aprovação no Comitê de Ética em Pesquisa na Universidade Estadual de Santa Cruz (UESC), sob o parecer de apreciação de número CAAE 63446716.8.0000.5526, as entrevistas foram realizadas.

As entrevistas foram direcionadas por um roteiro elaborado com perguntas principais norteadoras, complementadas por questões que surgiram de acordo com a dinâmica do diálogo, possibilitando a emergência de informações de forma mais livre, já que as respostas não foram condicionadas a uma padronização de alternativas. As entrevistas foram realizadas com todos os integrantes da Associação Doces e Segredos da Floresta, totalizando 13 associados, e coletadas por meio de gravação em câmera e gravador, acompanhada de registros fotográficos.

Após o término das gravações, a transcrição das entrevistas foi realizada de uma forma que se aproximou bastante na sua forma original, sendo fiel e pretendendo da melhor forma transformar um relato oral num texto escrito que seja de leitura inteligível. O estudo e análise das entrevistas transcritas foram fundamentadas de acordo com o referencial de Bardin (2010) sobre a análise de conteúdo. Esse método de análise compreende um conjunto de técnicas de investigação que, por meio de uma descrição objetiva, sistemática e quantitativa do conteúdo 
manifesto das comunicações, tem por finalidade a interpretação destas mesmas comunicações. Nesse sentido, a análise dos dados foi processada de forma cíclica, existindo um retorno periódico às entrevistas no intuito da busca dos significados precisos e permitindo a realização de inferências.

\section{RESULTADOS E DISCUSSÃO}

\subsection{O perfil dos entrevistados e suas nuances}

Nos dados de identificação de cada entrevistado, foram evidenciadas características como sexo, escolaridade, idade, profissão atual e outras ocupações, lugar de origem e frequência com que vai até as cidades próximas (Serra Grande, Ilhéus, Itacaré e Uruçuca). Todos esses dados permitiram inferir sobre a participação diferenciada referente ao sexo na associação e na comunidade, as formas de conhecimento e como este foi adquirido, a naturalidade e relação com o lugar em que vivem, além do tempo de moradia.

Entre todos os entrevistados associados, a predominância do sexo feminino é evidente, sendo apenas $15 \%$ do sexo masculino e $85 \%$ do sexo feminino. Essa característica sintetiza a expressiva participação das mulheres tanto na organização da associação quanto na liderança de atividades e projetos. As tomadas de decisões por parte das mulheres da associação mostram o quanto é necessário buscar e criar iniciativas em prol de uma melhor qualidade de vida.

Em relação à escolaridade, foi possível identificar que o grande número dos entrevistados tem o ensino fundamental I incompleto, equivalendo a $54 \%$ de seu total, sendo que os entrevistados estudaram apenas até a 2a ou 3a série. Um número de $23 \%$ conseguiu concluir o ensino médio e $8 \%$ relataram que nunca frequentaram a escola. Assim, o grau de escolaridade reflete a instrução dos moradores quanto às dificuldades de acesso ao ensino. A carência de escolas rurais é refletida no número de crianças e adultos que precisam ir para os centros urbanos em busca do ensino. Segundo o Censo Escolar da Educação Básica 2016 (2017), 89,8\% das escolas com ensino médio estão concentradas na zona urbana e 10,2\% na zona rural, tendo a menor participação da zona rural em toda a educação básica.

As idades dos moradores variam entre 24 e 60 anos, tendo uma média de 43 anos. Em relação à profissão ou ocupação dos entrevistados, todos trabalham com a agricultura, seja no cultivo de horta, seja em plantações de diversas culturas. Apenas 38\% dos associados já realizaram outro tipo de trabalho sem estar relacionado com a terra. Os relatos mostraram que em média os moradores vão uma ou duas vezes por semana à cidade, em momentos de extrema necessidade, como idas ao médico ou para fazer compras, passando a maior parte do tempo na comunidade.

Os dados revelaram que $54 \%$ dos entrevistados não são nativos da comunidade e $46 \%$ nasceram no Barrocão. Todos os entrevistados que não são nativos da comunidade vivem e convivem no lugar a um período de variação entre 7 e 38 anos, tendo o casamento como motivo exclusivo para morarem na comunidade. No entanto, 92\% dos entrevistados não nativos são mulheres, e, de acordo com Marin (2007) e Silvestro et al. (2001), esse cenário se materializa frequentemente no meio rural por questões de organização do trabalho nas unidades de produção familiar e processos sucessórios, que tendem a favorecer os homens na definição do herdeiro do patrimônio fundiário. 


\subsection{Valor Topofílico: o visto, o vivido e o percebido}

Sentir-se "parte" e "fazer" parte de algo se constitui no processo de compreensão do "eu" em comunhão com o mundo, com a realidade existente e as relações sociais estabelecidas no contexto vivido e em transformação. A organização social que permite essa íntima ligação com os elementos que a configuram e com o sentimento de pertença do sujeito é a comunidade. Distante de ser um consenso, a definição de comunidade abarca diferentes abordagens, pelo fato de apresentar dinamicidade e mudança ao longo do tempo.

O conceito de comunidade surgiu no intuito de se diferenciar do conceito de sociedade, com o qual é comumente confundido e utilizado como sinônimo. Para Tonnies (2002), a comunidade é baseada nas relações naturais, envolvidas por sentimentos como afetividade, amor, compreensão, gratidão e fidelidade, tendo a não racionalidade como orientadora das atitudes, na qual os indivíduos permanecem incorporados em um contexto vital amplo e orgânico, reconhecendo um ao outro nos seus respectivos estados. A sociedade já é baseada em relações racionais, voltadas para o egoísmo, individualismo, ambição econômica e ganância, em que as relações são estabelecidas por contratos recíprocos, reguladas por convenção social e leis.

No sentido de comunidade apresentado por Tonnies, a comunidade passa a ter uma delimitação que vai além das fronteiras e dos limites geográficos e espaciais estabelecidos. Esse fato é percebido pelo relato de um dos moradores, que reside em uma localidade que não é reconhecida como Barrocão, porém ele se sente parte dela: Eu me considero que moro no Barrocão, porque... por causa da associação, por causa da feira e é mais conhecido, né? Eu falo que fico na entrada do Barrocão, mas eu me considero um deles também (M. R., Barrocão, 34 anos).

$\mathrm{Na}$ fala do entrevistado, o pertencer à comunidade é fortalecido pela convivência, amizade, confiança e pelo trabalho associativo que unificou os interesses em comum. Essa noção de delimitação da comunidade se refere muito à noção de fronteiras comunitárias abordada por Cohen (1985), quando considera as fronteiras como delimitações mentais dos indivíduos, sendo uma construção simbólica, e que sua fluidez depende da subjetividade individual, crucial na fluidez da conceitualização da própria comunidade, alterando-se com as diferentes percepções e significados que cada um Ihe confere.

Os entrevistados se mostraram bastante contentes e satisfeitos em morar na comunidade. Os motivos relatados sobre gostar de morar no Barrocão foram tranquilidade, bem-estar, sossego, ser nativo da comunidade e o fato de ter a presença de floresta em volta. Além dos motivos citados, a autossuficiência alimentar foi um dos fatores mencionados por $21 \%$ dos entrevistados. A capacidade de produção de alimento para o consumo familiar é uma das características das comunidades rurais que ligam os agricultores com a terra e, consequentemente, com o lugar, como justifica um dos moradores: Aqui eu acho um lugar tranquilo, eu acho bom morar aqui, tem água à vontade, a gente não se preocupa com água, o ar também, as frutas. Na cidade, não... tudo a gente retira daqui, quase tudo, né, e na cidade, não... é quente, tudo que precisa tem que comprar (M. R., Barrocão, 34 anos).

Gazolla e Schneider (2007) afirmam que a produção para o autoconsumo proporciona a autonomia do agricultor, fazendo com que os moradores dependam cada vez menos do mercado e do comércio urbano para suprir as necessidades. Essa lógica permite a independência em relação ao mercado externo, a partir da valorização das práticas agricultáveis e da terra, conhecendo a procedência dos alimentos, e por meio dos valores sociofamiliares em todo o processo de produção. 
A dicotomia entre o rural e urbano aparece diversas vezes nos relatos dos moradores, tanto em relação a sua independência do sistema urbano como na qualidade de vida e bem-estar:

Aqui é calmo, eu gosto de calma e sossego, não gosto de agitação. Já morei muito tempo na cidade, gosto de lá de vez em quando para resolver uma coisa e voltar, mas para morar eu gosto daqui... da calma. (L. Barrocão, 40 anos).

Rapaz, porque sempre eu gostei de roça, eu não gosto de cidade. Aqui é calmo, a gente tem o espaço melhor, maior, plantar... até o ar que a gente toma é diferente de lá, lá é abafado, assim, a gente não tem a respiração livre, não, é abafado! (E.A.F., Barrocão, 57 anos).

A vida na cidade para os moradores é sinônimo de agitação, preocupação e má qualidade ambiental, principalmente por conta da poluição atmosférica. Dos $41 \%$ que citaram a problemática das cidades para moradia, apenas $8 \%$ nunca viveram nela. Os relatos se baseiam no distanciamento da vida urbana com o meio rural, onde a relação com a natureza é mais íntima, intensa e, por causa da dispersão populacional, nítida nas áreas não densamente povoadas, predominando a proximidade familiar na comunidade e vizinhança (ABRAMOVAY, 2000). Bagli (2006) também afirma que a paisagem pouco modificada no meio rural, apresentando menos mudanças em comparação com a paisagem urbana, intensifica a relação homem-meio, já que as modificações no seu espaço são pouco percebidas.

Apesar de os entrevistados se mostrarem felizes e gratificados por morarem na comunidade, alguns problemas foram mencionados: falta de escolas e transporte coletivo, dificuldade na comunicação e no atendimento à saúde, frequência de quedas de energia e má qualidade das estradas. As péssimas condições nas estradas que dão acesso à comunidade se tornaram a problemática que mais incomoda os moradores, impedindo melhorias na comunidade e no deslocamento. Diante dos problemas citados, os relatos se remeteram a problemas e dificuldades externas, como infraestrutura e serviços que deveriam ser administrados pela gestão municipal, e não por problemas internos ou ambientais.

Mesmo com os problemas destacados, $54 \%$ dos entrevistados nunca se imaginaram vivendo em outra localidade, tendo a comunidade não somente como um espaço para morar, mas como um lugar para viver. Essa mudança de concepção de "espaço" para "lugar" é o que envolve o relato dos moradores, em que lugar passa a ser um espaço qualificado, tornando-se percebido pela população por motivar experiências humanas a partir da apreensão de estímulos ambientais (CASTELLO, 2005). Matos (2010) complementa que o sentido de lugar atribuído pelos moradores pressupõe um "elo afetivo entre o indivíduo e o local, onde este sujeito se distancia de uma atitude indiferente e se aproxima de uma relação de identidade com este determinado local, ainda que de maneira efêmera". O elo entre os entrevistados e a comunidade se dá principalmente pelo sentimento de afeto e pelo bem viver com o que sabe fazer e com o que a terra proporciona: [...] gosto, adoro aqui. Porque é um lugar onde eu... é um lugar onde eu me sinto bem, né? É onde eu trabalho, é onde tenho minha roça, não pretendo sair daqui para morar fora, não! (M. L. O. S., Barrocão, 40 anos).

Entre os moradores, $46 \%$ disseram que já se imaginaram vivendo em outro lugar, em busca de emprego e para morar mais próximo da cidade. Porém, 12\% desses entrevistados têm receio de sair do campo para viver na cidade, por causa da violência e concorrência no mercado de trabalho. Apesar de ser grande o número de entrevistados que gostam de viver na comunidade e não pretendem sair, alguns moradores que não são nativos do Barrocão ainda têm ligação com 
o lugar de origem. Esse fato é relatado por um entrevistado que ainda almeja voltar para o lugar onde nasceu, mesmo depois de 20 anos vivendo na comunidade:

(Sobre o lugar onde morava) Era mais bonito, lá é mais alto porque aqui é muito baixo, lá é alto assim (levantando os braços) tudo alto, e aqui é mais no baixo... é mais barroca, tem muita barroca e o Pé de Serra, não... é alto, lá pega sinal qualquer hora e aqui, não, só pega com antena. (M.D.S., Barrocão, 52 anos).

Como descreve o relato, a localização do lugar que o torna mais bonito e a facilidade de comunicação são elementos que contribuem para o maior afeto com a localidade. No entanto, o "fenômeno da paisagem" que é percebido pelo morador não se resume apenas à sua composição geográfica, mas carrega em si todas as experiências vividas e lembranças daquele lugar, envolvendo manifestações afetivas, emocionais, familiares e cognitivas. Para Tuan (2012), a paisagem se remete a uma imagem integrada, a qual é constituída pela mente e pelos sentidos, residindo na íntima interação do sujeito com a paisagem, a partir de elementos objetivos e subjetivos, ou seja, aqueles que não se pode observar.

Assim, os aspectos antrópicos se apresentam como um fator distintivo para se pensar em paisagem por um viés mais social. A intenção neste trabalho não é discutir a construção do conceito de paisagem, mas é necessário seu entendimento para poder alcançar o fenômeno da percepção dos moradores. Dessa forma, o elo que o entrevistado ainda estabelece com o local onde nasceu e viveu uma grande parte de sua vida é influenciado por suas memórias individuais. Para Tuan (2012, p. 144), "a consciência do passado é um elemento importante no amor pelo lugar", remetendo-se aos laços estabelecidos com a natureza ou recorrendo à história, expondo a saudade do seu lar. Nesse sentido, sentir-se parte da comunidade atual em que vive não exclui o afeto com o lugar de origem.

Em relação à prática de atividades de lazer realizadas pelos moradores na comunidade (Figura 2), constatou-se a existência da divisão entre o lazer coletivo que necessita de outras pessoas para a interação e o lazer individual que não precisa da presença do outro para realizar qualquer tipo de atividade e ocupação. De acordo com os relatos, a distribuição das atividades de lazer por quantidade de citações se estruturou da seguinte maneira:

Figura 2 - Atividades de lazer realizadas pelos moradores

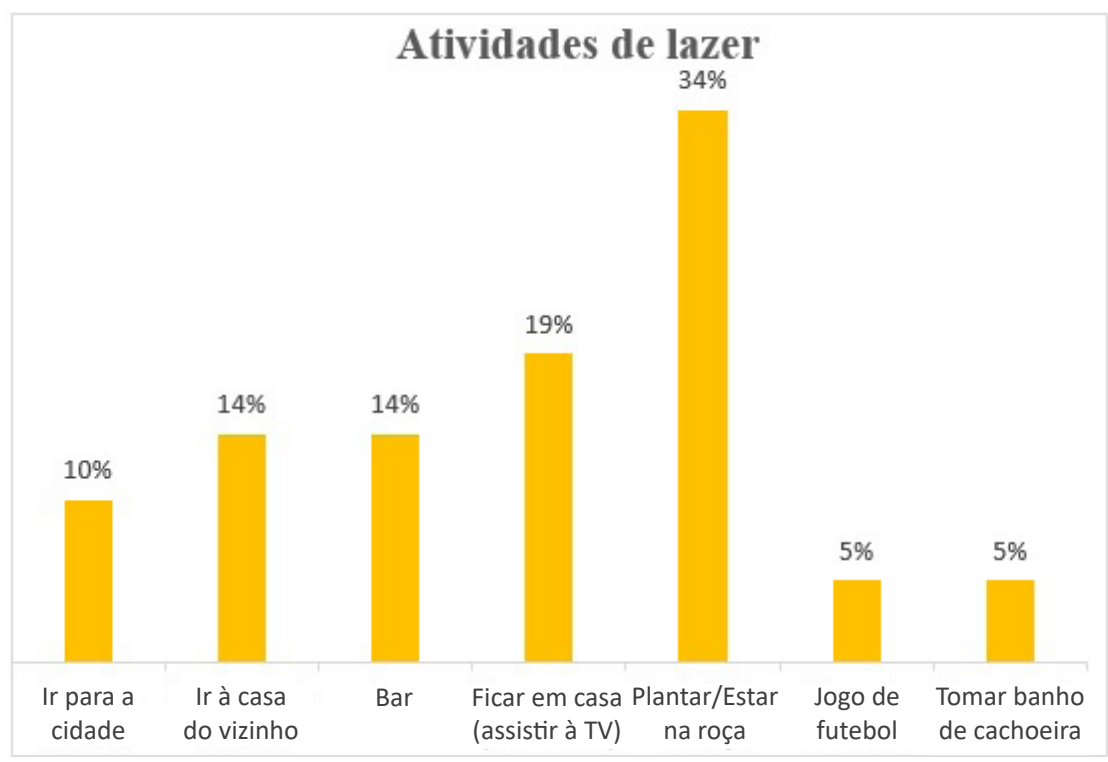

Fonte: Autoria própria, em 2017. 
Como mostra o gráfico, a atividade com maior porcentagem de citações foi estar presente na roça, ou seja, em seu ambiente de trabalho. Esse dado exemplifica as diversas formas de conceituar o que de fato é lazer para cada indivíduo na região rural e qual atividade se enquadra como prazerosa. Diante disto, percebe-se que nem sempre o lazer surge como oposição ao trabalho, mesmo reconhecendo a sua "criação" na era industrial como o tempo não produtivo do trabalhador. Segundo Martignoni e Corona (2013), por conta do antagonismo entre o trabalho e o lazer, este passou a ter um estatuto próprio com um tempo específico em contraposição ao tempo de trabalho, com espaços determinados, separados dos locais de trabalho e moradia.

A percepção de lazer dos moradores se distancia bastante da noção de lazer excludente do local de trabalho. Os relatos mostraram que os entrevistados se sentem bem e gratificados quando estão trabalhando na roça, utilizando seu tempo livre para cuidar da horta e da plantação:

Meu descanso... meu lazer é a roça mesmo, eu me sinto melhor estando fora de dentro de casa do que ficar dentro de casa. Quando estou na roça é meu lazer, e é bom mesmo... ohhh meu deus, ninguém me fala, ninguém me abusa, eu estou olhando meus pezinhos de coisa, converso com eles, eles me entendem e eu entendo eles, eles veem minha pressão e eu vejo a pressão deles, quando eles estão bons, eu venha [colhe] e salto fora. (E. A. F., Barrocão, 57 anos).

[...] eu gosto mesmo é de estar na minha horta, pelo menos ali, sei lá... estou vendo crescendo, depois arranca. Eu gosto do que faço, plantar. (E. S., Barrocão, 24 anos).

O olhar dos moradores para o prazer e bem-estar está diretamente associado ao produto final do trabalho e ao que se pode usufruir dele, tendo como a maior gratificação ver o resultado de todo o esforço e empenho colocado na plantação. Acompanhar o processo de desenvolvimento das culturas e a época da colheita se transformou em momento de descanso, prazer e satisfação, unindo o que eles gostam de fazer com o meio de sobrevivência.

A dificuldade da dissociação entre o trabalho e o lazer no meio rural consiste na relação de complementação e unidade existente entre ambos. Weiduschadt (2009) explica que, nas comunidades rurais, a separação entre trabalho e lazer é muito tênue, já que a dicotomia entre tempo de trabalho e tempo de lazer não aparece de forma tão explícita no trabalho ligado à agricultura, considerando que as principais manifestações de lazer das comunidades rurais parecem estar atreladas ao trabalho.

Nessa direção, entende-se que os moradores relacionam as formas de lazer a partir da perspectiva do trabalho, aproximando-se ou distanciando-se dele. A autonomia no trabalho agrícola se remete à noção do tempo e à forma como ele orienta as comunidades rurais, sendo que o tempo corresponde ao usufruto do momento presente, não se limitando aos períodos institucionalizados para o fenômeno do lazer (fim do dia, fim de semana, férias etc.) (GOMES, 2004), podendo ocorrer em qualquer momento e espaço-lugar.

Nesse sentido, Marin (2007) aponta que a necessidade de produções teóricas a respeito do lazer contemple outras realidades sociais que vão além do cenário urbano-industrial, o qual se baseia na forte dicotomia entre o trabalho e lazer. Para a autora, o reconhecimento das diversas realidades e contextos no qual diferentes grupos sociais estão inseridos possibilita uma leitura mais completa sobre a compreensão do lazer nas áreas rurais.

Com 23\% de citações, frequentar bares e ir na casa do vizinho são atividades que facilmente os moradores realizam. O lazer coletivo de se reunir com a vizinhança e ir a bares contempla o princípio da sociabilidade proposto por Elias e Dunning (1992), o qual é o elemento básico 
que faz parte das atividades comunitárias coletivas, onde se compartilha o prazer que é gerado pela reunião do grupo. A troca de conversas, sorrisos e emoções é convertida em prazeres que satisfazem o tempo livre de cada indivíduo, além de fortalecer o convívio social. Nos relatos, foi questionada a ausência de uma área de lazer comunitária, a qual possibilitasse a reunião dos moradores em um único espaço e tempo, visualizando-se, dessa forma, a sede da associação como um futuro espaço para a socialização dos moradores e ambiente de desenvolvimento de atividades miméticas, como assistir a filmes.

A ida para as cidades próximas foi citada apenas por 15\% dos entrevistados, mesmo estas tendo praias. Por dificuldade de locomoção e por preferirem um local de tranquilidade e sossego em seus períodos de lazer, os moradores preferem ficar na comunidade em vez de sair: [...] a gente já se acostumou aqui... o lazer é viver aqui dentro do mato mesmo [risos]. Quem mora na cidade é que vai para roça, que é o lazer, e a gente acha que o lazer é quando sai daqui e vai para cidade (M. L. O. S., Barrocão, 40 anos).

O trecho destacado reforça a inversão dos sentidos de lazer para as sociedades ditas modernas e para as comunidades rurais. Para os moradores da comunidade, a saída para a cidade quebra a rotina e Ihes coloca no princípio da mobilidade, proporcionando vivências de bem-estar que dificilmente realizarão novamente, como fazer uma viagem ou ir à praia. Contudo, o meio rural é visto pelos moradores urbanos como o ambiente de lazer ideal, fugindo de toda a dinâmica turbulenta e agitada da cidade e indo ao encontro do sossego e da tranquilidade do campo. Martignoni e Corona (2013) afirma que essa noção de lazer vivida pelos moradores das cidades se materializa como um fenômeno historicamente construído, resultado das necessidades históricas do homem, projetando o lazer como uma transformação de formas lúdicas e culturais do modo de vida das sociedades tradicionais, a partir de um modo de vida moderno.

O modo de vida moderno mencionado pelo autor é a tentativa da reaproximação das comunidades urbanas com a natureza, discutido por Carvalho (2012) como o fenômeno das novas sensibilidades que surgiu no século XVIII e se prolonga até os dias atuais. Essas sensibilidades nasceram dos efeitos da deterioração do meio ambiente nas cidades e em decorrência do interesse e da valorização da natureza pelos moradores. Por conta desse contexto histórico, nota-se a intensa necessidade de arborização nas cidades, programas ecológicos, criação de áreas verdes e, principalmente, do turismo rural.

\section{CONCLUSÃO}

Compreender a percepção ambiental dos moradores da comunidade rural do Barrocão foi o objetivo central e norteador de toda a pesquisa. A categoria valor topofílico auxiliou no processo investigativo para alcançar o objetivo definido, resultando em uma análise cíclica e sistêmica, como foi proposta na discussão metodológica da pesquisa.

A concepção de comunidade que os moradores têm vai além das delimitações geográficas, constituída pelas relações de amizade, convivência e confiança, assim como também pelo fato de estes compartilharem objetivos em comum na associação: um conjunto que produziu, um real e espontâneo sentimento de pertencimento. A autossuficiência alimentar foi a qualidade mais enfatizada durante os relatos. A capacidade de produzir seu próprio alimento, ter independência do mercado externo, saber a procedência dos alimentos e fortalecer os valores sociofamiliares durante o processo produtivo resultou na autonomia adquirida pelos agricultores e na forte ligação com a terra e o lugar em que vivem. 
A noção de lazer dos moradores se distanciou bastante da visão de lazer excludente do local de trabalho, a qual a sociedade moderna está acostumada, apresentando um estatuto próprio, com tempo e espaço determinados. Na comunidade rural, a separação entre o lazer e o trabalho na agricultura é muito sutil, já que a dicotomia entre o tempo de trabalho e tempo de lazer não é explícita. Acerca deste tema, percebe-se a carência de produções teóricas que discutam o lazer no ambiente rural, considerando a heterogeneidade dos diferentes grupos sociais neste ambiente.

Assim, as diferentes perspectivas, sentidos e olhares que acabam configurando um mundo tão subjetivo e particular do sujeito se tornaram essenciais para direcionar o mundo material e a realidade em que este indivíduo está inserido. Desta maneira, o acesso ao mundo do outro nos leva a repensar nossas próprias práticas e comportamentos perante o ambiente que nos cerca, como também serve para fundamentar a elaboração de programas comunitários, aprimorar o plano de manejo e incentivar a inclusão nas tomadas de decisões, em direção à melhora da qualidade de vida e ambiental.

\section{REFERÊNCIAS}

SILVESTRO, Milton Luiz; ABRAMOVAY, Ricardo; MELLO, Márcio Antonio de; DORIGON, Clovis; BALDISSERA, Ivan Tadeu. Os impasses sociais da sucessão hereditária na agricultura familiar. Florianópolis: Epagri, 2001.

ABRAMOVAY, Ricardo. Funções e medidas da ruralidade no desenvolvimento contemporâneo. Rio de Janeiro: IPEA, 2000. [Texto para discussão n. 702]. Disponível em: https://www.ipea.gov.br/portal/images/ stories/PDFs/TDs/td_0702.pdf. Acesso em: 10 fev. 2018.

ALVES, José Eustáquio Diniz. Do antropocentrismo ao ecocentrismo: uma mudança de paradigma. In: MARTINE, George (Ed./Org.). População e sustentabilidade na era das mudanças ambientais globais: contribuições para uma agenda brasileira. 1. ed. Belo Horizonte: ABEP, 2012. p. 299-310.

BAGLI, Priscila. Rural e urbano: harmonia e conflito na cadência da contradição. In: SPOSITO, Maria Encarnação Beltrão; WHITACKER, Arthur Magon (Ed./Org.). Cidade e campo: relações e contradições entre urbano e rural. 2. ed. São Paulo: Expressão Popular, 2006. p. 81-109.

BAHIA (Estado). Plano de Manejo do Parque Estadual da Serra do Conduru. Serra Grande: Ministério do Meio Ambiente, 2005.

BARDIN, Laurence. Análise de conteúdo. 4. ed. Lisboa: Edições 70, 2010.

CARVALHO, Isabel Cristina Moura. A questão ambiental e a emergência de um campo de ação políticopedagógica. In: LOUREIRO, Carlos Frederico Bernardo; LAYRARGUES, Philippe Pomier; CASTRO, Ronaldo Souza (Ed./Org.). Sociedade e meio ambiente: a educação ambiental em debate. 7. ed., São Paulo: Cortez, 2012. p. 55-69.

CASTELLO, Lineu. Repensando o lugar no projeto urbano: variações na percepção de lugar na virada do milênio (1985-2004). 2005. 435f. Tese (Doutorado em Arquitetura) - Universidade Federal do Rio Grande do Sul, Porto Alegre, RS, 2005.

COHEN, Anthony P. The symbolic construction of community. London: Tavistock, 1985.

CORREIA, Augusto Manoel. A agricultura familiar versus agricultura de subsistência no âmbito da segurança alimentar no espaço dos países da CPLP. In: Segurança Alimentar e Nutricional na Comunidade dos Países de Língua Portuguesa: desafios e perspectivas. Rio de Janeiro: Fundação Fiocruz / Instituto de Higiene e Medicina Tropical, 2013. p. 119-33. 
ELIAS, Norbert; DUNNING, Eric. A busca da excitação: desporto e lazer no processo civilizacional. Lisboa: Difel, 1992.

GAZOLLA, Marcio; SCHNEIDER, Sergio. A produção da autonomia: os "papéis" do autoconsumo na reprodução social dos agricultores familiares. Revista Estudos Sociedade e Agricultura, Rio de Janeiro, v. 15, n. 1, p. 89-122, 2007.

GOMES, Christiane Luce. Verbete Lazer - Ocorrência histórica. In: GOMES, Christianne Luce (Org.). Dicionário crítico do lazer. Belo Horizonte: Autêntica, 2004. p. 133-41.

GOMES, Diogo Antonio Queiroz. Análise da visitação pública no Parque Estadual da Serra do Conduru (PESC)-BA. In: CONGRESSO NORTE-NORDESTE DE PESQUISA E INOVAÇÃO - CONNEPI, 7., Palmas, 19 a 21 de outubro, 2012. Anais [...]. Tocantins: Instituto Federal de Educação, Ciência e Tecnologia, 2012.

HALL, Stuart. A identidade cultural na pós-modernidade. 11. ed. Rio de Janeiro: DP\&A, 2006.

INSTITUTO NACIONAL DE ESTUDOS E PESQUISAS EDUCACIONAIS ANÍSIO TEIXEIRA (INEP). Censo Escolar da Educação Básica 2016 - notas estatísticas. Brasília: MEC, 2017.

LE BOSSÉ, Mathias. As questões de identidade em geografia cultural - algumas concepções contemporâneas. In: CORRÊA, Roberto Lobato; ROSENDAHL, Zeny (Org.). Paisagens, textos e identidade. Rio de Janeiro: EdUERJ, 2004. p. 157-79.

LYNCH, Kevin. A imagem da cidade. 3. ed. São Paulo: Martins Fontes, 2011.

MARIN, Elizara Carolina. O lúdico na vida. Revista Conexões, Campinas, v. 2, n. 1, p. 32-46, 2007.

MARTIGNONI, Luciano; CORONA, Hieda Maria Pagliosa. Lazer e a ruralidade contemporânea para além da racionalidade capitalista. DRd - Desenvolvimento Regional em debate, Canoinhas, v. 3, n. 1, p. 145, maio/2013.

MATOS, Marcelo Pereira. A sensibilidade do lugar: uma proposta metodológica para aplicação da percepção ambiental nos planos de emergência a derrames de óleo. Orientadora: Solange Terezinha de Lima Guimarães. 2010. Tese (Doutorado em Geografia) - Universidade Estadual Paulista, Instituto de Geociências e Ciências Exatas, Rio Claro, SP, 2010.

MASSON, Ivanete. A gestão ambiental participativa: possibilidades e limites de um processo de múltiplas relações. 2004. Dissertação (Mestrado em Engenharia Ambiental) - Universidade Federal de Santa Catarina, Centro Tecnológico, Florianópolis, SC, 2004.

OKAMOTO, Jun. Percepção ambiental e comportamento: visão holística da percepção ambiental na arquitetura e comunicação. São Paulo: Editora Mackenzie, 2002.

TONNIES, Ferdinand. Community and Society. Nova Iorque: Dove Publication, 2002.

TUAN, Yi-Fu. Topofilia: um estudo da percepção, atitudes e valores do meio ambiente. Londrina: Eduel, 2012.

WEIDUSCHADT, Patricia. O lazer e a construção da identidade numa comunidade rural de descendentes germânicos em Pelotas. Cadernos do LEPAARQ - Textos de Antropologia, Arqueologia e Patrimônio, Pelotas, v. 6, n. 11/12, p. 22, 2009.

WHYTE, Anne. Guidelines for field studies in Environmental Perception. Technical Notes 5. Paris: UNESCO, 1977. 


\section{Sobre as autoras:}

Damile de Jesus Ferreira: Doutoranda em Desenvolvimento e Meio Ambiente na Universidade Estadual de Santa Cruz (UESC). Mestra em Desenvolvimento Regional e Meio Ambiente pela UESC, Bahia. Especialista em Educação Ambiental pela Faculdade de Educação São Luís. Licenciada em Ciências Biológicas pela Universidade Estadual de Feira de Santana (UEFS). E-mail: damileferreira@yahoo.com.br, Orcid: https://orcid.org/0000-0003-3475-9974

Christiana Cabicieri Profice: Doutora em Psicologia Social pela Universidade Federal do Rio Grande do Norte (UFRN). Mestra em Psicologia Clínica e Patológica pela Université de Paris V (René Descartes) e em Desenvolvimento Regional e Meio Ambiente pela Universidade Estadual de Santa Cruz (UESC). Graduada em Psicologia pela Universidade Santa Úrsula (USU). Professora da USU e de Educação Ambiental no Programa de Pós-Graduação em Desenvolvimento Regional e Meio Ambiente (PRODEMA/UESC), orientando investigações em nível de mestrado. E-mail: ccprofice@uesc.br, Orcid: https://orcid.org/0000-0002-1972-9622 
